\title{
Chiari malformation type I and basilar invagination originating from atlantoaxial instability: a literature review and critical analysis
}

\author{
Arthur Wagner $^{1}$ (D) Lukas Grassner ${ }^{2} \cdot$ Nikolaus Kögl $^{2} \cdot$ Sebastian Hartmann ${ }^{2} \cdot$ Claudius Thomé $^{2} \cdot$ Maria Wostrack $^{1}$. \\ Bernhard Meyer ${ }^{1}$
}

Received: 14 April 2020 / Accepted: 22 May 2020 / Published online: 6 June 2020

(C) The Author(s) 2020

\begin{abstract}
Introduction Recently, a novel hypothesis has been proposed concerning the origin of craniovertebral junction (CVJ) abnormalities. Commonly found in patients with these entities, atlantoaxial instability has been suspected to cause both Chiari malformation type I and basilar invagination, which renders the tried and tested surgical decompression strategy ineffective. In turn, $\mathrm{C} 1-2$ fusion is proposed as a single solution for all CVJ abnormalities, and a revised definition of atlantoaxial instability sees patients both with and without radiographic evidence of instability undergo fusion, instead relying on the intraoperative assessment of the atlantoaxial joints to confirm instability.

Methods The authors conducted a comprehensive narrative review of literature and evidence covering this recently emerged hypothesis. The proposed pathomechanisms are discussed and contextualized with published literature.

Conclusion The existing evidence is evaluated for supporting or opposing sole posterior C1-2 fusion in patients with CVJ abnormalities and compared with reported outcomes for conventional surgical strategies such as posterior fossa decompression, occipitocervical fusion, and anterior decompression. At present, there is insufficient evidence supporting the hypothesis of atlantoaxial instability being the common progenitor for $\mathrm{CVJ}$ abnormalities. Abolishing tried and tested surgical procedures in favor of a single universal approach would thus be unwarranted.
\end{abstract}

Keywords Atlantoaxial fusion $\cdot$ Atlantoaxial instability $\cdot$ Basilarinvagination $\cdot$ C1-2 fusion $\cdot$ Chiari malformation $\cdot$ Syringomyelia

\section{Introduction}

Time and again, hypotheses that had been approved as collective understandings of pathogenetic interactions are challenged and put into question. For the purposes of a thriving academia, it is equally as important to recognize these novel hypotheses as genuine avant-garde endeavors to further our scientific culture as it is mandatory to test and scrutinize them

Arthur Wagner and Lukas Grassner contributed equally to this work.

This article is part of the Topical Collection on Spine - Other

Arthur Wagner

arthur.wagner@tum.de

1 Department of Neurosurgery, Klinikum rechts der Isar, Technical University Munich School of Medicine, Ismaninger Str. 22, 81675 Munich, Germany

2 Department of Neurosurgery, Medical University Innsbruck, Innsbruck, Austria for scientific validity. In this nature, we may bear witness to a fundamental change in the way we perceive and understand the group of entities encompassing malformations of the craniovertebral junction (CVJ), mainly represented by the Chiari malformation type I (CM, Fig. 1) and basilar invagination (BI, Fig. 2). The academic community owes the recently sparked discourse on this intricate topic to Prof. Atul Goel, who has been pioneering his hypothesis that addresses the very principles of CVJ abnormalities and their genesis. Based on his longstanding and accredited experience on the surgical treatment of CVJ abnormalities in several original investigations, Goel was able to formulate an assumption that would entail a drastic change in the way these entities are treated surgically $[30,32,33,35,37,38]$. His proposals have been met with both enthusiasm and dismissal, but no thorough review of his hypothesis against the available evidence has been conducted yet $[8,51,53,94]$. In this paper, we examine publications supporting or opposing Goel's hypothesis based on their respective clinical results. 
Fig. 1 Chiari malformation type with syringomyelia in a 46-yearold female. Magnetic resonance imaging, sagittal (a) and axial (b) planes

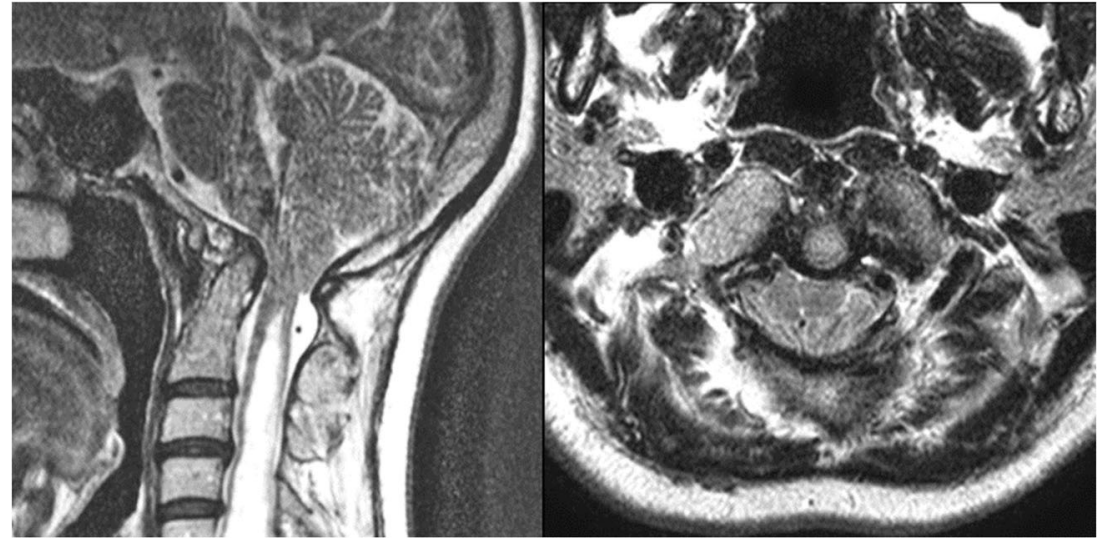

\section{Definitions}

Due to the manifold nomenclatures and criteria that govern the diagnosis of a CVJ malformation, it is crucial to settle definitions before proceeding with any discussion. The CVJ entities have traditionally been regarded as developmental anomalies that generally manifest in the pediatric population or in the middle stages of adulthood [38, 73]. The terminology has been compounded in the past and only crystallized with the increasing number of publications diverting their attention to this matter, while basilar invagination designates the primary, developmentally formed invasion of the odontoid process into the foramen magnum, basilar impression refers to a secondarily acquired protrusion due to softening of the skull, whereas cranial settling is specifically reserved for rheumatoid arthritis. In addition, both $\mathrm{CM}$ and $\mathrm{BI}$ are closely associated with syringomyelia and purportedly share common pathomechanisms involving compromised cerebrospinal fluid (CSF) dynamics at the CVJ, that remain improperly understood $[3,14,25$, 27, 46, 47]. Despite these uncertainties, surgical treatment has seen favorable results for both $\mathrm{CM}$ and BI with low complication rates in the last decades $[1,17,22,46,60$, $84,97]$. The surgical strategies principally aim at increasing the posterior fossa volume in $\mathrm{CM}$ by suboccipital decompression, relieving brain stem compression in $\mathrm{BI}$ by a ventral approach or suboccipital decompression, and an occipitocervical stabilization procedure when

Fig. 2 Basilar invagination in a 62-year-old female. Computed tomography, sagittal (a) and coronal (b) planes; magnetic resonance imaging, sagittal plane (c)

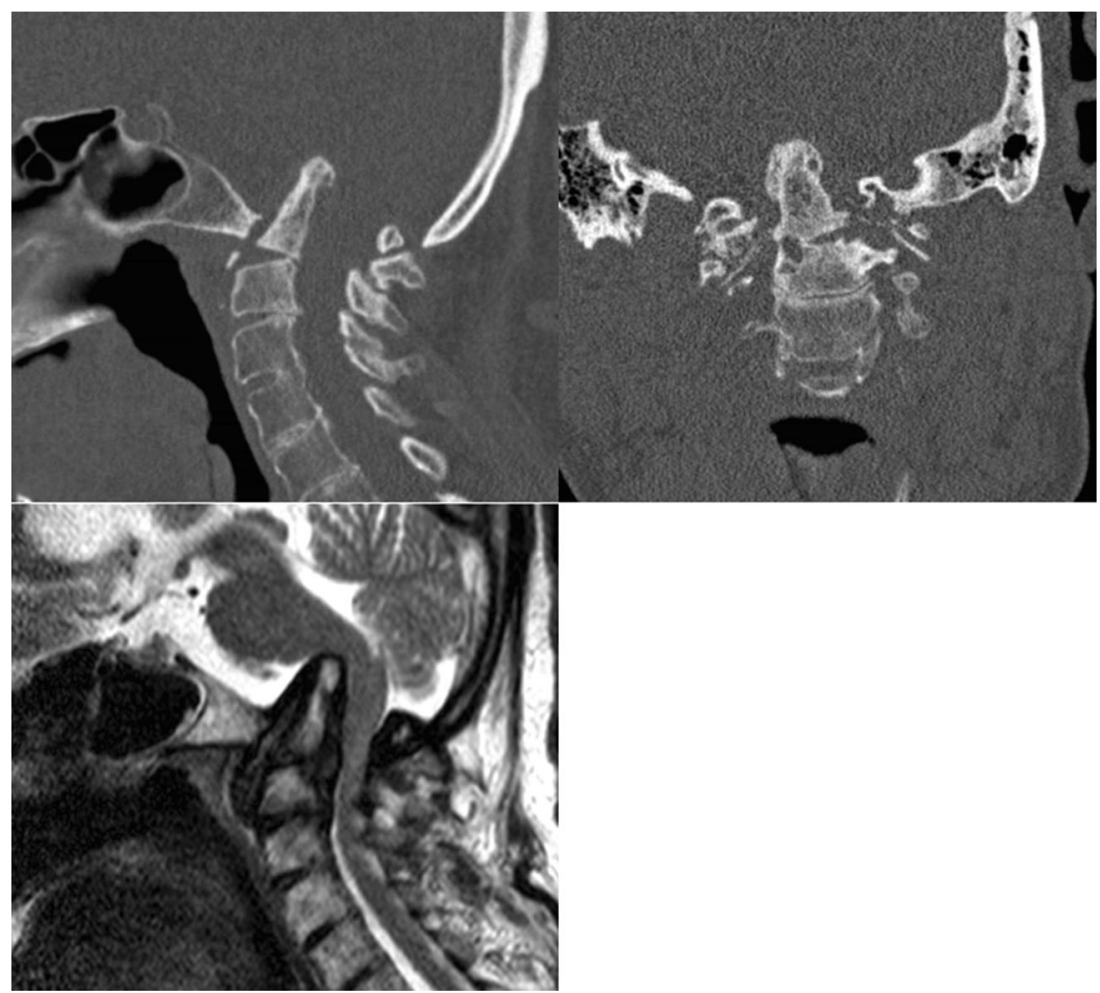


instability of the CVJ is evident $[60,66,73]$. Contrasting these principles, Goel seeks to define a common denominator for the complex of CVJ abnormalities in the form of "central atlantoaxial instability," which is to be addressed universally by sole atlantoaxial stabilization without any decompression procedure [33, 37].

The definitions of atlantoaxial instability itself vary throughout literature as do the treatment guidelines [26, 45]. Commonly, lateral radiographs of the $\mathrm{CVJ}$ demonstrating an atlantodental interval of at least $3 \mathrm{~mm}$ in adults and $5 \mathrm{~mm}$ in children indicate instability, whereas newer investigations by computed tomography set the cut-off at $2 \mathrm{~mm}$ for adults $[50,59,80,81,93]$. This definition accounts for the most commonly encountered anterior displacement of atlantoaxial instability, while Fielding and Hawkins alternatively devised a classification with respect to the direction of the atlantoaxial dislocation [26]. The heterogeneity of definitions may equally be founded in the lack of a comprehensive assessment of a healthy control group, which only few morphometric studies have undertaken so far. Some distinguishing hallmarks were identified, although they tend to differ between studies $[5,75,96]$.

In a most recent publication, Lacy et al. only consider anterior displacements of the atlas over the axis by more than $5 \mathrm{~mm}$ and posterior displacements unstable and in need of surgical treatment, whereas rotatory facetal subluxation and translation by less than $5 \mathrm{~mm}$ should be evaluated for conservative treatment or surgery in selected cases [63]. By the distinction between stable and unstable atlantoaxial dislocation, virtually, all authors differ fundamentally to Goel's hypothesis, which seeks to predefine a universal instability even without any radiographic abnormality [33].

\section{Methods}

Relevant literature for this narrative review was compiled by two independent reviewers, who conducted an online literature search on October 24, 2019. Our search strategy was applied to the following databases: PubMed/Medline and ISI Web of Science. These were queried for the following keywords and MeSH (medical subject headings) terms: "Chiari malformation," "Chiari malformation type I," "atlantoaxial instability," "craniocervical decompression," atlantoaxial fusion," "posterior fossa decompression." After finding a consensus on eligible articles by both reviewers, studies were included in this narrative review. Relevant articles identified via cross-referencing were also included, if they directly concerned the abovementioned group of entities in an investigative manner.

The principal items of interest extracted from the collected studies were the study types, patient numbers, surgical procedures, rates of complications, and symptomatic improvements as well as follow-up duration. Ultimately, each clinical study's results were assessed for them supporting or objecting the hypothesis of atlantoaxial instability producing CVJ abnormalities. In addition, we first provided a cohesive outline of the numerous articles published by Goel, which cover this particular subject.

\section{Results}

\section{Goel's hypothesis}

Goel introduced and developed explanations for the association of the primary CVJ abnormalities over the course of several publications. In his series of 190 surgically treated patients with $\mathrm{BI}$, a clear methodological distinction was achieved to subdivide his cohort into group I without associated CM and group II with associated CM [38]. Mechanistically, he declared the dissociation of the odontoid from the anterior arch of the atlas to be pivotal for its upward migration and posterior angulation, thereby directly compromising the foramen magnum and compressing the brain stem. This presupposed instability of both the atlantoaxial and atlantooccipital complexes in group I patients. Group II patients in contrast exhibited upward migration of atlas, axis, and clivus in unison, which primarily produced a reduction of the posterior fossa volume and downward herniation of the cerebellar tonsils [38]. On this premise, selection of an appropriate surgical strategy incorporating ventral decompression, posterior decompression, posterior stabilization of the $\mathrm{CVJ}$, or a combination of these would be feasible.

It is important to note that Goel manufactured the distinction on the basis of CM's presence exclusively and deduced the aspect of facetal joint instability post hoc [29]. He renamed the labels to group A and group B in 2009, now prioritizing the observation of facetal instability in group A [29]. His focus on facetal orientation with subsequent instability of the naturally very mobile atlantoaxial joint as a pivotal factor deviated from the conventional view of atlantodental instability as a primary initiator. In Goel's universal CVJ model, syringomyelia fits as a tertiary response to the reduced posterior fossa volume in CM (group B) patients [39]. He established a logical sequence of craniovertebral instability leading to atlantoaxial dislocation and thus the complex of CM, BI, and syringomyelia in 2005, when he first applied his philosophy in 12 patients undergoing C1-2 fixation without any form of decompression [44].

In 2009, Goel started to critically review the then current treatment paradigms for CVJ [29]. Based on his own observations, he began to differentiate the instability of group A patients from a primarily congenital pathogenesis without evidence of instability of the CVJ in group B patients. His hypothesis was underpinned by a craniometric study of 170 patients, the majority of which was conducted retrospectively. Treating patients with the unstable form of BI (group A) only by intraoperative atlantoaxial facetal distraction and stabilization resulted in an 
increase of craniovertebral height, neck length, and cervical lordosis in over $90 \%$ of individuals [43]. Goel thus argues that these pathomorphological hallmarks, which have been described numerous times since Klippel and Feil in 1912 and Chamberlain in 1939 , are all subject to reversal, once the primary initiating neural compression has been alleviated [12, 23]. Several musculoskeletal changes, such as a short neck, assimilation of the atlas, neutralization of the craniospinal angulation, and a reduced cervical motion range, are thus merely natural adaptations [29, 34].

By extension, the development of $\mathrm{CM}$ with downward herniation of the tonsils would serve as a protective, sacrificial measure to mitigate compression on the brain stem, hence coining the term Nature's protective air bag in his 2014 and 2015 publications $[31,33]$. In his most controversially discussed feature, a portion of Goel's cohort of patients did not exhibit any apparent preoperative atlantoaxial instability evident by facetal slippage on dynamic radiographs, but still underwent $\mathrm{C} 1-2$ stabilization. His assumption on this central instability or type III atlantoaxial dislocation being the driving pathogenetic factor was then validated intraoperatively by manual manipulation [33, 35]. Goel had, by then, uniformly resorted to C1-2 stabilization as a solution to both group A unstable BI and group B stable (fixed) BI with or without $\mathrm{CM}$, abandoning any form of foramen magnum decompression. Ultimately, he deems any decompression procedure to be akin to deflating the air bag, which would only serve a temporary clinical effect and may be detrimental in the long run $[33,53]$. In numerous further clinical and radiological studies, Goel consolidated his hypothesis mainly by reporting favorable clinical and electrophysiological recovery for adult and pediatric cohorts, albeit without offering substantial radiographic evidence for changes of syringomyelia and without methodologically tailored control groups to his cohorts [37, 41, 42, 86]. The resolution of suboccipital headaches, neck pain, and muscle spasms, even in the absence of manifest neural compression, inevitably validates the proposed pathomechanisms, he argues [36].

A thus far neglected element of Goel's proposal lies in the long-term implications of craniocervical fusion in a generally adolescent population, which may affect the sagittal balance of the subaxial spine, height growth, and quality of life of children. Kennedy et al. report on favorable outcomes after craniocervical fusion in children, although a proportion of the cohort may experience difficulties in compensating for the fused segments [56]. The patient-reported outcomes seem to be satisfying, however, although no study has examined a homogenous CM population undergoing C1-2 fixation only [49, 79, 91].

\section{Basilar invagination—current treatment paradigm}

The evolution of BI treatment has seen considerable advances within the recent decades, although not without controversies $[15,19,20,38,55,60,61,71,73,74,85]$. While it is equivocally agreed upon that incidental findings warrant conservative management, a consensus on a treatment algorithm for a progressive clinical deterioration has yet to be established, which may be owed to the diversity of $\mathrm{CVJ}$ abnormalities and their mutual interactions [58, 92].

The pathomechanisms that need to be addressed surgically are found in the instability, which manifests itself in a reducible BI, and the neural compression that may be directed from anterior or posterior. In 1980, Menezes and co-workers proposed a treatment algorithm tailored to these mechanisms, employing reduction and occipitocervical stabilization as a first measure for reducible $\mathrm{BI}$ and decompression from either anterior or posterior for irreducible BI [74]. In those cases with evidence of postoperative instability after decompression, a fusion procedure was carried out of variable extent via bone graft. The surgical techniques were refined consequently, with Goel often opting for C12 stabilization with lateral mass screws and rods in 1998, in addition to suboccipital craniectomy with duraplasty for associated CM and transoral decompression for irreducible BI [38].

Klekamp et al. reported their series of 323 patients with $\mathrm{CM}$ and $\mathrm{BI}$ undergoing treatment according to a refined algorithm [60]. Essentially, the algorithm intends for posterior fossa decompression (PFD) alone only when there are no signs of CVJ instability, ventral compression of the brain stem, and segmentation anomalies, regardless of the presence of BI. In any other case, a posterior stabilization, which extended from the occiput to $\mathrm{C} 2$, was added to the PFD. A transoral decompression was reserved for those patients presenting with caudal cranial nerve deficits caused by ventral compression. Klekamp's rationale to primarily conduct a posterior stabilization for patients with assimilation of the atlas but a stable BI was to preemptively address postoperative instability, which he and others have observed in this specific subgroup. He argued that decompression alone eventually leads to musculoskeletal decompensation and debilitating chronic neck pain syndromes when no adjunct stabilization is performed simultaneously [60].

The principal decision-making has not been altered much since, although technical modifications to the anterior approaches continue to be investigated $[21,95]$.

\section{Chiari malformation type I-definitions}

$\mathrm{CM}$ is defined as a descent of the cerebellar tonsil of at least $5 \mathrm{~mm}$ into the upper cervical canal. Several pathogenic mechanisms have been proposed. They can be divided mainly into (1) a volumetric disproportion between the posterior fossa and its contents (reduced embryologic development of the skull base), (2) hemodynamic/cerebrospinal fluid dynamic alterations resulting in increased intracranial pressure, (3) mass effect within the posterior fossa (e.g., tumors), and (4) low intraspinal pressure due to craniospinal intrathecal pressure imbalance (e.g., lumbo-peritoneal shunts) [9]. A detailed understanding of the underlying mechanism of the cerebellar tonsil descent is crucial for managing this cohort [67]. 
Noteworthy, CM may be associated with CVJ deformities. The simultaneous presence of craniocervical instability and the need for a proper preoperative work-up has been widely accepted. Initially, instability was mainly noted after suboccipital decompression and laminectomy [2]. Over time, failure of conventional surgical management has been attributed to coexisting craniocervical anomalies requiring reduction and OCF procedures [6]. In 2011, Tubbs and colleagues shared their surgical experience of 500 cases with pediatric $\mathrm{CM}$ over 2 decades. They identified several deformities in their cohort: $18 \%$ presented with spinal anomalies including scoliosis, $24 \%$ had a retroversion of the odontoid process, $3 \%$ a Klippel-Feil anomaly, and $8 \%$ an atlantooccipital fusion [90]. Logically, it is important to recognize subluxation, as failure to do so may result in clinical deterioration after decompressive surgery for $\mathrm{CM}$, especially when laminectomy of the atlas is also performed [13]. The reported association of CM-I and atlantoaxial subluxation is around $30 \%[13,65,76]$. Further another group tried to identify risk factors for the requirement of additional $\mathrm{OCF}$ in pediatric $\mathrm{CM}$ patients. In their retrospective review, concomitant $\mathrm{BI}$ and a clivoaxial angle below $125^{\circ}$ have been identified to be associated with the need of OCF [6].

\section{Discussion}

\section{Basilar invagination-discussion of evidence}

It is essential to understand that Goel proposes a definitive uniform solution for a heterogeneous spectrum of CVJ abnormalities. By identifying atlantoaxial instability as a common denominator for CM, BI, atlantoaxial dislocation, and syringomyelia, it is possible to employ a single tried and tested technique as the entire management. To our knowledge, there is only one study that strictly reproduced Goel's strategy of reduction and C1-2 stabilization without any decompression (Table 1) [83]. Most authors naturally undertake reduction of a dislocation whenever possible, in addition to stabilization in the reduced position and optional decompression measures when there is brain stem compression not amenable by reduction. Fusion usually extends to the occiput.

This strategy has been applied consistently by Menezes and Van Gilder in 1980 with significant functional improvement in each of their 17 cases [74]. Although the cohort was fairly heterogeneous at baseline, including cases with rheumatoid arthritis and traumatic atlantoaxial dislocation, the authors were the first to conceive a structured treatment algorithm, tailored to the primary pathology. They prioritized reduction of any atlantoaxial dislocation and its stabilization, while decompression measures were secondary for irreducible pathologies [74]. In a later study with pediatric patients suffering from osteogenesis imperfecta, their treatment algorithm was reapplied. Despite preoperative traction and successful occipitocervical fusion (OCF), BI progressed in $80 \%$ radiographically after completed management, although most of these were aged between 11 and 15 years and only $24 \%$ exhibited a recurrence of symptomatic brain stem compression [85]. In this publication, Menezes expressed the hypothesis of atlantoaxial instability being the progenitor of $\mathrm{BI}$ and other CVJ abnormalities, as he recognized that pediatric patients had a higher rate of reducible BI due to atlantoaxial instability than adult patients, where it had become fixed [70].

In the following years, several case reports and small series were published with strategies similar to Menezes' [16, 48, $55,57,58,68,87]$. The outcomes of all of these were reported to be excellent, although the populations were mainly pediatric. Goel et al. reported on an instantaneous benefit by traction for $82.0 \%$ of their BI patients without CM, while only $5 \%$ of those with CM improved immediately after traction [38].

Subsequently, a number of clinical studies reported outcomes after variable combinations of circumferential approaches with posterior reduction and fusion as well as posterior and anterior decompression, although the level of evidence is generally low (Table 1).

In a meta-analysis from 2017, different PFD techniques were compared across 27 pooled studies [17]. A postoperative improvement was noted in up to $85.0 \%$ of patients compared with a complication rate of $13.5 \%$ over 1451 patients with BI and/or CM. Details on radiological outcome or the rate of posterior fusions were not provided and only one study was reported as being randomized with methodological shortcomings, however.

In 2008, Fenoy and Menezes reported on 234 patients with $\mathrm{CM}$ and associated unstable CVJ abnormalities [24]. The authors comprised a catalog of instability criteria to screen their database of CVJ patients for instability and proceeded to fuse all of them from occiput to $\mathrm{C} 2$ or $\mathrm{C} 3$ with optional decompression measures. Again, postoperative improvement was noted in $92 \%$. While some of the patients did not undergo any decompression procedure in addition to OCF, the authors do not provide exact reasoning for this decision-making.

In one of the most comprehensive series, Klekamp reported improvements in $81.6 \%$ of patients with $\mathrm{CM}$ and $\mathrm{BI}$ after treatment according to a predefined algorithm [60]. Among all patients, $14.2 \%$ had CM with $\mathrm{BI}$ and these were treated with sole PFD in $41.3 \%$ of cases compared with $95.3 \%$ in the $\mathrm{CM}$ without $\mathrm{BI}$ subgroup. The complication rate was significantly higher in the $\mathrm{CM}$ with $\mathrm{BI}$ group (35.6\%) than in the $\mathrm{CM}$ without BI group (16.4\%). Despite the higher proportion of fusion procedures in the $\mathrm{CM}$ with $\mathrm{BI}$ group, the radiographic reduction of syringomyelia occurred less often postoperatively [60]. In comparison, Goel and co-workers found a much higher incidence of BI with $\mathrm{CM}$ with $84.0 \%$, and while also reporting an excellent improvement rate with $96.2 \%$ overall, only 6 out of 11 patients showed radiographic reduction of 


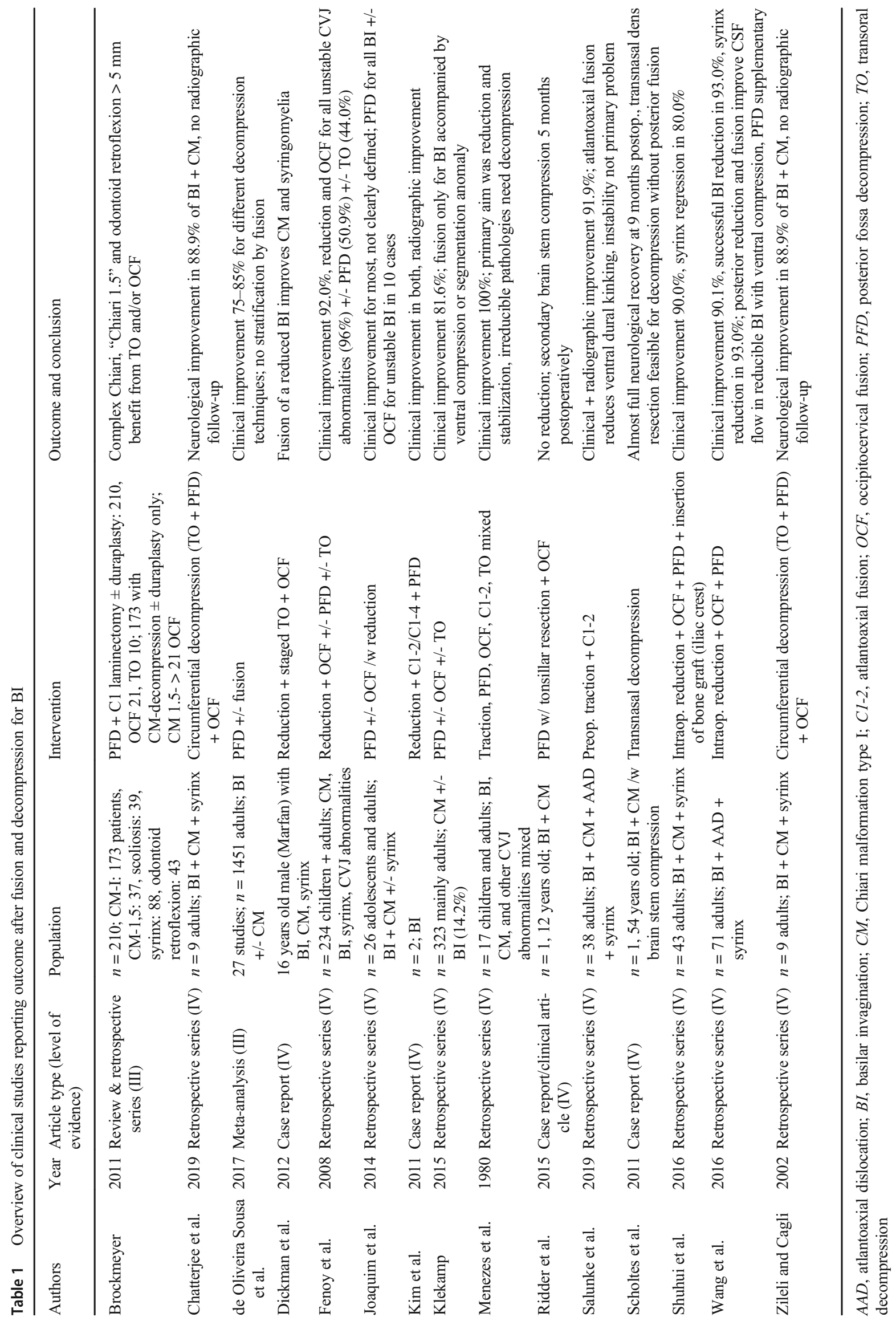


tonsillar herniation and syringomyelia [33]. In a later pediatric series, Goel and colleagues again used reduction and C1-2 instrumentation for CM with both unstable and fixed BI [40]. The authors report successful and sustained reduction in all patients, concomitant with marked clinical improvement.

The reason for postoperative improvement should thus be attributed in large part to the reduction, which indirectly decompresses the brain stem by a protruding odontoid, and partially in the stabilization, which serves to sustain this effect. This hypothesis was proposed by other authors [71, 83, 92]. Wang et al. analyzed the reduction of syrinx volume and CVJ alignment in 71 patients treated with OCF and bony suboccipital decompression after reduction. They found that for $93.0 \%$ of patients with satisfying reposition of the odontoid, a syrinx regression was achieved as well [92]. In a recent study, Salunke and colleagues reduced and fused 38 patients with $\mathrm{CM}$ and $\mathrm{BI}$, of which $91.9 \%$ maintained both clinical and radiographical improvement after 6 months [83]. The authors did not conduct any craniectomy for decompression, as they conclude that the downward traction and repositioning of the odontoid suffices for indirect compression of the brain stem by neutralizing kinking of the dura. This supposedly services reestablishment of the CSF flow through the foramen magnum and enables reversal of the tonsillar herniation, which was observed in their study. Interestingly, all patients with iatrogenic dural laceration showed transient clinical worsening [83]. A PFD would likewise increase the posterior fossa volume and make space for the protective air bag, but not address the inherent pathogenetic mechanism, they argue. PFD therefore remains effective in treating the sequelae of $\mathrm{CM}$ with or without $\mathrm{BI}$, albeit with a substantial risk for recurrence of CSF obstruction after decompression: in Klekamp's study, the recurrence rates after PFD for CM without BI significantly increase with time and the number of surgeries performed, whereas those for $\mathrm{CM}$ with $\mathrm{BI}$ decrease with time and are mostly attributable to hardware failure [60].

Joaquim et al. applied a different surgical strategy for BI with concomitant CM in 2014. In their series of 26 patients, all but one underwent PFD primarily, while 9 patients with clear atlantoaxial instability on preoperative flexion radiographs received OCF as well [52]. Most of the patients improved clinically after an average follow-up of 9 months, although no radiographic follow-up was reported to evaluate the development of tonsillar herniation and odontoid migration.

It should be noted that, while Goel intentionally limited his instrumentation to $\mathrm{C} 1-2$, more than half of his reported patients exhibited an assimilated atlas, which biomechanically rendered his C1-2 approach an OCF in many cases [33]. As pointed out by Jea and Goel himself, exposing the joints and screw insertion sites of the atlas may impose substantial risk to the vertebral arteries and extradural venous plexuses of the CVJ, which appears wholly unjustified when considering the possibility of an OCF in case of an already existing atlas assimilation instead $[33,42,51]$.
The aforementioned observations emphasize the need to critically reconsider abolishing a toolkit of surgical strategies in favor of a single one, especially when there may be absent preoperative evidence of the decisive atlantoaxial instability in a significant number of cases, i.e., a Type III instability. More so than any author so far, it is commendable that Goel strives for a more streamlined solution, which in turn makes for an uneven comparison of the outcomes between his and other series. Relying on a one size fits all procedure is certainly warranted for a subgroup of patients, for whom unstable BI represents the primary CVJ abnormality. The current state of evidence, however, does not allow for an unequivocal adoption of his novel hypothesis, even when his outcomes and expertise have produced compelling results. This argument is further emphasized by the excellent outcomes and complication rates of established treatment strategies.

A comparison of surgical strategies in a representable patient cohort under controlled circumstances is necessary, since the delicate mechanistic explanations are difficult to prove without studies employing homogeneous methodologies and focuses.

\section{Chiari malformation type I-discussion of evidence}

As mentioned above, several processes can lead to or are coexisting with CM. Hence, a detailed understanding is necessary to provide a case-based approach. Over time, several treatment options have been introduced. As pointed out by Brockmeyer, it is important to recognize "complex" Chiari cases as they may require additional surgical interventions aside from a typical suboccipital decompression [7].

PFD with or without duraplasty (PFDD) has been and is still widely used. To date, the largest meta-analysis dealing with PFD +/- PFDD by Chai et al. demonstrated that both procedures are effective options in most cases [11]. PFDD is associated with a larger reduction in syrinx size, but with a higher incidence of CSF leakage and aseptic meningitis. Despite these favorable results, it has to be mentioned that resolution of syringomyelia has been shown after posterior C1-C2 distraction and fusion as well [82].

Over time, it has been increasingly recognized that patients with $\mathrm{CM}$ and concomitant $\mathrm{CVJ}$ abnormalities are more likely to deteriorate clinically after PFD $[13,72]$. This may be especially true for patients receiving PFD plus $\mathrm{C} 1$ laminectomy with (undiagnosed) AAD. In a single center retrospective analysis on patients with pediatric CM types 1 and 1.5 by Brockmeyer, 210 patients were identified who received surgery. PFD with $\mathrm{C} 1$ laminectomy was performed in all cases and OCF was needed in around $10 \%$ of all patients. Notably, none of the CM type I patients required OCF or odontoid resection, but more than half of patients with the more complex CM type 1.5 underwent OCF and more than $20 \%$ received additional odontoid resection [7]. Still, the PFD 
technique represents an established surgical procedure adopted and pursued by the majority of specialists involved with the treatment of CM. Several studies on long-term outcome provide testament to excellent results. Reported success rates reach $84 \%$ even after 5 years of follow-up as well as negligible surgical morbidity and mortality [28, 62, 88, 89]. These results have to be opposed with the outcome of the novel C1-2 fixation strategy, for which long-term outcome is still sparse [33].

In the aforementioned comparative study by Klekamp, the influence of concomitant $\mathrm{BI}$ in patients with $\mathrm{CM}$ pathology was clearly demonstrated [60]. Out of 323 CM-I patients, 46 $(14.2 \%)$ also had BI. PFDD was performed in all cases without $\mathrm{BI}$ and OCF was added in only 4 patients due to instability. In patients with concomitant BI but no ventral cord compression, PFD was also conducted. The strategy changed in cases with ventral spinal cord compression, where transoral decompression followed by posterior decompression and fusion was conducted. Hence, he concluded that CM patients without BI or with BI but no significant ventral spinal cord compression can be managed by PFD alone. The issue of secondarily progressive instability after PFD is a particularly controversial topic without profound evidence. Again, reports on postoperative instability range widely between 9 and $95 \%$, being relegated to retrospective case series and case reports with varying definitions $[2,4,10,64,69]$. Generally, most authors seem to be concerned predominantly about instability after anterior decompression of the odontoid and consistently report instability rates of $72 \%$ with significant neurological morbidity $[60,77,78]$.

By Goel's theory, all CM patients have subtle or radiologically apparent atlantoaxial instability, which is the hallmark of the pathophysiological cascade [33]. We fully agree that the coexistence of BI and AAD with CM should not be missed with the available data nowadays $[13,84]$. However, previous studies clearly demonstrated clinical efficacy with decompression alone and probably remains a suitable treatment option for $\mathrm{CM}$ with no signs of instability [11,54]. In summary, we agree with Deora and colleagues that in patients with pure CM with symmetrical $\mathrm{C} 1 / 2$ joints and no signs of instability, PFD and duraplasty is an established, effective, and safe treatment option with excellent long-term outcome [18, 28, 62, 89]. In patients with instability, C1-2 fusion with distraction or OCF with or without transoral decompression in selected cases are potential treatment options that have to be considered in this patient population.

\section{Conclusion}

During recent years, a novel treatment strategy for CVJ abnormalities has been developed, with atlantoaxial instability being declared the abnormalities' original cause. We conducted a narrative literature review of the evidence for this topic, which primarily stems from retrospective investigations and case reports. As current evidence does not clearly support or refute this hypothesis, prospective controlled studies incorporating functional and patient-focused outcome parameters are necessary before unequivocally adopting one single treatment strategy.

Funding information Open Access funding provided by Projekt DEAL.

\section{Compliance with ethical standards}

Conflict of interest The authors declare that they have no conflict of interest.

Ethical approval This article reviews studies involving human participants. To the best of our knowledge, the included studies were in accordance with the 1964 Helsinki declaration and its later amendments or comparable ethical standards.

Informed consent As no human participants were included in our study, the need for informed consent was not applicable.

Open Access This article is licensed under a Creative Commons Attribution 4.0 International License, which permits use, sharing, adaptation, distribution and reproduction in any medium or format, as long as you give appropriate credit to the original author(s) and the source, provide a link to the Creative Commons licence, and indicate if changes were made. The images or other third party material in this article are included in the article's Creative Commons licence, unless indicated otherwise in a credit line to the material. If material is not included in the article's Creative Commons licence and your intended use is not permitted by statutory regulation or exceeds the permitted use, you will need to obtain permission directly from the copyright holder. To view a copy of this licence, visit http://creativecommons.org/licenses/by/4.0/.

\section{References}

1. Alzate JC, Kothbauer KF, Jallo GI, Epstein FJ (2001) Treatment of Chiari I malformation in patients with and without syringomyelia: a consecutive series of 66 cases. Neurosurg Focus 11:E3-E3. https:// doi.org/10.3171/foc.2001.11.1.4

2. Aronson DD, Kahn RH, Canady A, Bollinger RO, Towbin R (1991) Instability of the cervical spine after decompression in patients who have Arnold-Chiari malformation. J Bone Joint Surg Am 73:898-906

3. Batzdorf U, McArthur DL, Bentson JR (2013) Surgical treatment of Chiari malformation with and without syringomyelia: experience with 177 adult patients. J Neurosurg 118:232-242. https://doi.org/ 10.3171/2012.10.JNS12305

4. Bekelis K, Duhaime AC, Missios S, Belden C, Simmons N (2010) Placement of occipital condyle screws for occipitocervical fixation in a pediatric patient with occipitocervical instability after decompression for Chiari malformation. J Neurosurg Pediatr 6:171-176. https://doi.org/10.3171/2010.4.peds09551

5. Besachio DA, Khaleel Z, Shah LM (2015) Odontoid process inclination in normal adults and in an adult population with Chiari malformation type I. J Neurosurg Spine 23:701-706. https://doi. org/10.3171/2015.3.spine14926 
6. Bollo RJ, Riva-Cambrin J, Brockmeyer MM, Brockmeyer DL (2012) Complex Chiari malformations in children: an analysis of preoperative risk factors for occipitocervical fusion. J Neurosurg Pediatr 10:134-141. https://doi.org/10.3171/2012.3.peds 11340

7. Brockmeyer DL (2011) The complex Chiari: issues and management strategies, Neurological sciences: official journal of the Italian Neurological Society and of the Italian Society of Clinical Neurophysiology. 32(Suppl 3):S345-S347. https://doi.org/10. 1007/s10072-011-0690-5

8. Brockmeyer DL, Oakes WJ, Rozzelle C, Johnston J, Rocque BG, Anderson RCE, Feldstein N, Martin J, Tuite GF, Rodriguez L, Wetjen N, Aldana P, Pincus D, Storm P, Proctor MR, Lew S (2015) Chiari malformation Type 1 and atlantoaxial instability: a letter from the Pediatric Craniocervical Society. J Neurosurg Spine 23:820-821. https://doi.org/10.3171/2015.3.SPINE15233

9. Buell TJ, Heiss JD, Oldfield EH (2015) Pathogenesis and cerebrospinal fluid hydrodynamics of the Chiari I malformation. Neurosurg Clin N Am 26:495-499. https://doi.org/10.1016/j.nec.2015.06.003

10. Camino Willhuber GO, Bosio ST, Puigdevall MH, Halliburton C, Sola CA, Maenza RA (2017) Craniocervical spinal instability after type 1 Arnold Chiari decompression: a case report. J Pediatr Orthop B 26:80-85. https://doi.org/10.1097/bpb.0000000000000346

11. Chai Z, Xue X, Fan H, Sun L, Cai H, Ma Y, Ma C, Zhou R (2018) Efficacy of posterior fossa decompression with duraplasty for patients with Chiari malformation type I: a systematic review and meta-analysis. World Neurosurgery 113:357-365.e351. https:// doi.org/10.1016/j.wneu.2018.02.092

12. Chamberlain WE (1939) Basilar impression (platybasia): a bizarre developmental anomaly of the occipital bone and upper cervical spine with striking and misleading neurologic manifestations. Yale J Biol Med 11:487-496

13. Chatterjee S, Shivhare P, Verma SG (2019) Chiari malformation and atlantoaxial instability: problems of co-existence. Child Nerv Syst 35:1755-1761. https://doi.org/10.1007/s00381-019-04284-z

14. Chiari H (1891) Ueber Veränderungen des Kleinhirns infolge von Hydrocephalie des Grosshirns 1. DMW - Deutsche Medizinische Wochenschrift 17:1172-1175. https://doi.org/10.1055/s-00291206803

15. Crockard HA (1988) Anterior approaches to lesions of the upper cervical spine. Clin Neurosurg 34:389-416

16. Dahdaleh NS, Dlouhy BJ, Menezes AH (2012) Application of neuromuscular blockade and intraoperative $3 \mathrm{D}$ imaging in the reduction of basilar invagination. J Neurosurg Pediatr 9:119-124. https:// doi.org/10.3171/2011.11.PEDS11332

17. de Oliveira SU, de Oliveira MF, Heringer LC, Barcelos ACES, Botelho RV (2018) The effect of posterior fossa decompression in adult Chiari malformation and basilar invagination: a systematic review and meta-analysis. Neurosurg Rev 41:311-321. https://doi. org/10.1007/s10143-017-0857-5

18. Deora H, Behari S, Sardhara J, Singh S, Srivastava AK (2019) Is cervical stabilization for all cases of Chiari-I malformation an overkill? Evidence speaks louder than words! Neurospine 16:195-206. https://doi.org/10.14245/ns.1938192.096

19. Dickman CA, Kalani MYS (2012) Resolution of cervical syringomyelia after transoral odontoidectomy and occipitocervical fusion in a patient with basilar invagination and type I Chiari malformation. J Clin Neurosci 19:1726-1728. https://doi.org/10.1016/j.jocn. 2012.04.006

20. Dickman CA, Locantro J, Fessler RG (1992) The influence of transoral odontoid resection on stability of the craniovertebral junction. J Neurosurg 77:525-530. https://doi.org/10.3171/jns.1992.77. 4.0525

21. El-Sayed IH, Wu J-C, Dhillon N, Ames CP, Mummaneni P (2011) The importance of platybasia and the palatine line in patient selection for endonasal surgery of the craniocervical junction: a radiographic study of 12 patients. World Neurosurgery 76:183178. https://doi.org/10.1016/j.wneu.2011.02.018

22. Erdogan E, Cansever T, Secer HI, Temiz C, Sirin S, Kabatas S, Gonul E (2010) The evaluation of surgical treatment options in the Chiari malformation type I. Turkish Neurosurgery 20:303-313. https://doi.org/10.5137/1019-5149.JTN.2648-09.2

23. Feil A, Klippel (1912) Un cas d'absence des vertébres cervicales cage thoracique remontant jusqu'a la base du crâne. Bull Mém Soc Anthropol Paris:101-102

24. Fenoy AJ, Menezes AH, Fenoy KA (2008) Craniocervical junction fusions in patients with hindbrain herniation and syringohydromyelia. J Neurosurg Spine 9:1-9. https://doi.org/10. 3171/SPI/2008/9/7/001

25. Fernández AA, Guerrero AI, Martínez MI, Vázquez MEA, Fernández JB, Chesa i Octavio E, Labrado JDIC, Silva ME, de Araoz MFdGF, García-Ramos R, Ribes MG, Gómez C, Valdivia JI, Valbuena RN, Ramón JR. (2009) Malformations of the craniocervical junction (Chiari type I and syringomyelia: classification, diagnosis and treatment). BMC Musculoskelet Disord 10(Suppl 1):S1-S1. https://doi.org/10.1186/1471-2474-10-S1-S1

26. Fielding JW, Hawkins J, Ratzan SA (1976) Management of atlantoaxial instability. Bull N Y Acad Med 52:752-760

27. Gardner WJ (1977) Syringomyelia. Surg Neurol 7:370-370

28. Giammattei L, Messerer M, Daniel RT, Aghakhani N, Parker F (2017) Long term outcome of surgical treatment of Chiari malformation without syringomyelia. J Neurosurg Sci. https://doi.org/10. 23736/s0390-5616.17.04063-2

29. Goel A (2009) Basilar invagination, Chiari malformation, syringomyelia: a review. Neurol India 57:235-246. https://doi.org/10. 4103/0028-3886.53260

30. Goel A (2014) Is Chiari malformation nature's protective "air-bag"? Is its presence diagnostic of atlantoaxial instability? J Craniovertebr Junction Spine 5:107-109. https://doi.org/10.4103/0974-8237. 142302

31. Goel A (2014) Is Chiari malformation nature's protective "airbag"? Is its presence diagnostic of atlantoaxial instability? J Craniovertebr Junction Spine 5:107-109. https://doi.org/10.4103/ 0974-8237.142302

32. Goel A (2015) Craniovertebral junction instability: a review of facts about facets. Asian Spine J 9:636-644. https://doi.org/10.4184/asj. 2015.9.4.636

33. Goel A (2015) Is atlantoaxial instability the cause of Chiari malformation? Outcome analysis of 65 patients treated by atlantoaxial fixation. J Neurosurg Spine 22:116-127. https://doi.org/10.3171/ 2014.10.spine14176

34. Goel A (2016) Atlantoaxial instability: analyzing and reflecting on the nature's reparative games. J Craniovertebr Junction Spine 7:69 71. https://doi.org/10.4103/0974-8237.181823

35. Goel A (2018) Basilar invagination, syringomyelia and Chiari formation and their relationship with atlantoaxial instability. Neurol India 66:940-942. https://doi.org/10.4103/0028-3886.236992

36. Goel A (2018) Suboccipital pain in Chiari formation: its cause and significance. J Craniovertebr Junction Spine 9:221-222. https://doi. org/10.4103/jcvjs.JCVJS_117_18

37. Goel A (2019) A review of a new clinical entity of 'central atlantoaxial instability': expanding horizons of craniovertebral junction surgery. Neurospine 16:186-194. https://doi.org/10. 14245/ns.1938138.069

38. Goel A, Bhatjiwale M, Desai K (1998) Basilar invagination: a study based on 190 surgically treated patients. J Neurosurg 88:962-968. https://doi.org/10.3171/jns.1998.88.6.0962

39. Goel A, Desai K (2000) Surgery for syringomyelia: an analysis based on 163 surgical cases. Acta Neurochir 142:293-302. https://doi.org/10.1007/s007010050038

40. Goel A, Gore S, Shah A, Dharurkar P, Vutha R, Patil A (2018) Atlantoaxial fixation for Chiari 1 formation in pediatric age-group 
patients: report of treatment in 33 patients. World Neurosurgery 111:e668-e677. https://doi.org/10.1016/j.wneu.2017.12.137

41. Goel A, Jain S, Shah A (2018) Radiological evaluation of 510 cases of basilar invagination with evidence of atlantoaxial instability (group A basilar invagination). World Neurosurgery 110:533543. https://doi.org/10.1016/j.wneu.2017.07.007

42. Goel A, Sathe P, Shah A (2017) Atlantoaxial fixation for basilar invagination without obvious atlantoaxial instability (group B basilar invagination): outcome analysis of 63 surgically treated cases. World Neurosurgery 99:164-170. https://doi.org/10.1016/j.wneu. 2016.11.093

43. Goel A, Shah A (2009) Reversal of longstanding musculoskeletal changes in basilar invagination after surgical decompression and stabilization. J Neurosurg Spine 10:220-227. https://doi.org/10. 3171/2008.12.SPINE08499

44. Goel A, Sharma P (2005) Craniovertebral junction realignment for the treatment of basilar invagination with syringomyelia: preliminary report of 12 cases. Neurol Med Chir 45:512-518. https://doi. org/10.2176/nmc.45.512

45. Greenberg AD (1968) Atlanto-axial dislocations. Brain J Neurol 91:655-684. https://doi.org/10.1093/brain/91.4.655

46. Guyotat J, Bret P, Jouanneau E, Ricci AC, Lapras C (1998) Syringomyelia associated with type I Chiari malformation. A 21year retrospective study on 75 cases treated by foramen magnum decompression with a special emphasis on the value of tonsils resection. Acta Neurochir 140:745-754. https://doi.org/10.1007/ s007010050175

47. Heiss JD, Jarvis K, Smith RK, Eskioglu E, Gierthmuehlen M, Patronas NJ, Butman JA, Argersinger DP, Lonser RR, Oldfield EH (2019) Origin of syrinx fluid in syringomyelia: a physiological study. Neurosurgery 84:457-468. https://doi.org/10.1093/neuros/nyy072

48. Hsu W, Zaidi HA, Suk I, Gokaslan ZL, Wolinsky J-P (2010) A new technique for intraoperative reduction of occipitocervical instability. Neurosurgery 66:319-324. https://doi.org/10.1227/01.NEU. 0000369925.81522 .60

49. Hwang SW, Gressot LV, Rangel-Castilla L, Whitehead WE, Curry DJ, Bollo RJ, Luerssen TG, Jea A (2012) Outcomes of instrumented fusion in the pediatric cervical spine. J Neurosurg Spine 17:397409. https://doi.org/10.3171/2012.8.spine12770

50. Jackson H (1950) The diagnosis of minimal atlanto-axial subluxation. Br J Radiol 23:672-674. https://doi.org/10.1259/0007-128523-275-672

51. Jea A (2015) Chiari malformation I surgically treated with atlantoaxial fixation. J Neurosurg Spine 22:113-114. https://doi. org/10.3171/2014.9.SPINE14893

52. Joaquim A, Ghizoni E, Giacomini L, Tedeschi H, Patel A (2014) Basilar invagination: Surgical results. J Craniovertebr Junction Spine 5:78-84. https://doi.org/10.4103/0974-8237.139202

53. Joaquim AF (2015) Atlantoaxial instability and Chiari malformation. J Neurosurg Spine 22:559-559. https://doi.org/10.3171/2014. 12.SPINE141194

54. Joaquim AF, Tedeschi H, Chandra PS (2018) Controversies in the surgical management of congenital craniocervical junction disorders - a critical review. Neurol India 66:1003-1015. https://doi. org/10.4103/0028-3886.237025

55. Joseph V, Rajshekhar V (2003) Resolution of syringomyelia and basilar invagination after traction. Case illustration. J Neurosurg 98: 298-298. https://doi.org/10.3171/spi.2003.98.3.0298

56. Kennedy BC, D'Amico RS, Youngerman BE, McDowell MM, Hooten KG, Couture D, Jea A, Leonard J, Lew SM, Pincus DW, Rodriguez L, Tuite GF, Diluna ML, Brockmeyer DL, Anderson RC (2016) Long-term growth and alignment after occipitocervical and atlantoaxial fusion with rigid internal fixation in young children. $\mathrm{J}$ Neurosurg Pediatr 17:94-102. https://doi.org/10.3171/2015.5. peds 14728
57. Kim IS, Hong JT, Sung JH, Byun JH (2011) Vertical reduction using atlantoaxial facet spacer in basilar invagination with atlantoaxial instability. J Korean Neurosurg Soc 50:528-531. https://doi.org/10.3340/jkns.2011.50.6.528

58. Kim LJ, Rekate HL, Klopfenstein JD, Sonntag VKH (2004) Treatment of basilar invagination associated with Chiari I malformations in the pediatric population: cervical reduction and posterior occipitocervical fusion. J Neurosurg 101:189-195. https://doi.org/10.3171/ped.2004.101.2.0189

59. King JE, Brumley MA (2005) What is atlantoaxial instability? Nursing 35:71. https://doi.org/10.1097/00152193-20051100000060

60. Klekamp J (2015) Chiari I malformation with and without basilar invagination: a comparative study. Neurosurg Focus 38:E12-E12. https://doi.org/10.3171/2015.1.FOCUS14783

61. Klimo P Jr, Rao G, Brockmeyer D (2007) Congenital anomalies of the cervical spine. Neurosurg Clin N Am 18:463-478. https://doi. org/10.1016/j.nec.2007.04.005

62. Kurzbuch AR, Jayamohan J, Magdum S (2019) Decompressive surgery for Chiari I malformation in children without dural repair: a still effective and safe procedure? Child Nerv Syst 35:1839-1846. https://doi.org/10.1007/s00381-019-04241-w

63. Lacy J, Bajaj J, Gillis CC (2020) Atlantoaxial instability. In: StatPearls. StatPearls Publishing Copyright (C) 2020, StatPearls Publishing LLC., Treasure Island (FL),

64. Lam FC, Irwin BJ, Poskitt KJ, Steinbok P (2009) Cervical spine instability following cervical laminectomies for Chiari II malformation: a retrospective cohort study. Child Nerv Syst 25:71-76. https://doi.org/10.1007/s00381-008-0694-5

65. Levy WJ, Mason L, Hahn JF (1983) Chiari malformation presenting in adults: a surgical experience in 127 cases. Neurosurgery 12: 377-390. https://doi.org/10.1227/00006123-198304000-00003

66. Liao C, Visocchi M, Zhang W, Li S, Yang M, Zhong W, Liu P (2019) The relationship between basilar invagination and Chiari malformation type I: a narrative review. Acta Neurochir Suppl 125:111-118. https://doi.org/10.1007/978-3-319-62515-7 16

67. Loukas M, Shayota BJ, Oelhafen K, Miller JH, Chern JJ, Tübbs RS, Oakes WJ (2011) Associated disorders of Chiari type I malformations: a review. Neurosurg Focus 31:E3. https://doi.org/ 10.3171/2011.6.focus11112

68. McGirt MJ, Attenello FJ, Sciubba DM, Gokaslan ZL, Wolinsky J-P (2008) Endoscopic transcervical odontoidectomy for pediatric basilar invagination and cranial settling. Report of 4 cases. J Neurosurg Pediatr 1:337-342. https://doi.org/10.3171/PED/2008/1/4/337

69. McLaughlin MR, Wahlig JB, Pollack IF (1997) Incidence of postlaminectomy kyphosis after Chiari decompression. Spine 22: 613-617. https://doi.org/10.1097/00007632-199703150-00007

70. Menezes AH (1995) Primary craniovertebral anomalies and the hindbrain herniation syndrome (Chiari I): data base analysis. Pediatr Neurosurg 23:260-269. https://doi.org/10.1159/000120969

71. Menezes AH (1997) Craniovertebral junction anomalies: diagnosis and management. Semin Pediatr Neurol 4:209-223. https://doi.org/ 10.1016/S1071-9091(97)80038-1

72. Menezes AH, Greenlee JD, Donovan KA (2005) Honored guest presentation: lifetime experiences and where we are going: Chiari I with syringohydromyelia-controversies and development of decision trees. Clin Neurosurg 52:297-305

73. Menezes AH, VanGilder JC. (1988) Transoral-transpharyngeal approach to the anterior craniocervical junction. 69:895. https://doi. org/10.3171/jns.1988.69.6.0895

74. Menezes AH, VanGilder JC, Graf CJ, McDonnell DE (1980) Craniocervical abnormalities. A comprehensive surgical approach. J Neurosurg 53:444-455. https://doi.org/10.3171/jns.1980.53.4. 0444

75. Milhorat TH, Bolognese PA, Nishikawa M, McDonnell NB, Francomano CA (2007) Syndrome of occipitoatlantoaxial 
hypermobility, cranial settling, and chiari malformation type I in patients with hereditary disorders of connective tissue. J Neurosurg Spine 7:601-609. https://doi.org/10.3171/spi-07/12/601

76. Milhorat TH, Chou MW, Trinidad EM, Kula RW, Mandell M, Wolpert C, Speer MC (1999) Chiari I malformation redefined: clinical and radiographic findings for 364 symptomatic patients. Neurosurgery 44:1005-1017. https://doi.org/10.1097/00006123199905000-00042

77. Mouchaty H, Perrini P, Conti R, Di Lorenzo N (2009) Craniovertebral junction lesions: our experience with the transoral surgical approach. Eur Spine J 18(Suppl 1):13-19. https://doi.org/ 10.1007/s00586-009-0988-7

78. Naderi S, Pamir MN (2001) Further cranial settling of the upper cervical spine following odontoidectomy. Report of two cases. J Neurosurg 95:246-249. https://doi.org/10.3171/spi.2001.95.2. 0246

79. Ottenhausen M, Alalade AF, Rumalla K, Nair P, Baaj A, Hartl R, Kacker A, Greenfield JP, Anand VK, Schwartz TH (2018) Quality of life after combined endonasal endoscopic odontoidectomy and posterior suboccipital decompression and fusion. World Neurosurgery 116:e571-e576. https://doi.org/10.1016/j.wneu. 2018.05.041

80. Passias PG, Wang S, Kozanek M, Wang S, Wang C (2013) Relationship between the alignment of the occipitoaxial and subaxial cervical spine in patients with congenital atlantoxial dislocations. J Spinal Disord Tech 26:15-21. https://doi.org/10.1097/ BSD.0b013e31823097f9

81. Rojas CA, Bertozzi JC, Martinez CR, Whitlow J (2007) Reassessment of the craniocervical junction: normal values on CT. AJNR Am J Neuroradiol 28:1819-1823. https://doi.org/10. 3174/ajnr.A0660

82. Salunke P, Karthigeyan M, Malik P. (2019) Foramen magnum decompression without bone removal: $\mathrm{C} 1-\mathrm{C} 2$ posterior fixation for Chiari with congenital atlantoaxial dislocation/basilar invagination. Surg Neurol Int 10:38. https://doi.org/10.25259/sni-38-2019

83. Salunke P, Karthigeyan M, Malik P, Panchal C. (2019) "Changing perception but unaltered reality": how effective is C1-C2 fixation for Chiari malformations without instability? World neurosurgery: S1878-8750(1819)33154-33157. https://doi.org/10.1016/j.wneu. 2019.12.122

84. Salunke P, Sura S, Futane S, Aggarwal A, Khandelwal NK, Chhabra R, Mukherjee KK, Gupta SK (2012) Ventral compression in adult patients with Chiari 1 malformation sans basilar invagination: cause and management. Acta Neurochir 154:147-152. https:// doi.org/10.1007/s00701-011-1215-y

85. Sawin PD, Menezes AH (1997) Basilar invagination in osteogenesis imperfecta and related osteochondrodysplasias: medical and surgical management. J Neurosurg 86:950-960. https://doi.org/10. 3171/jns.1997.86.6.0950

86. Shah A, Patil A, Vutha R, Thakar K, Goel A (2019) Recovery of transcranial motor evoked potentials after atlantoaxial stabilization for Chiari formation: report of 20 cases. World Neurosurgery 127 : e644-e648. https://doi.org/10.1016/j.wneu.2019.03.236

87. Simsek S, Yigitkanli K, Belen D, Bavbek M (2006) Halo traction in basilar invagination: technical case report. Surg Neurol 66:311314. https://doi.org/10.1016/j.surneu.2005.12.029

88. Sindou M, Chávez-Machuca J, Hashish H (2002) Cranio-cervical decompression for Chiari type I-malformation, adding extreme lateral foramen magnum opening and expansile duroplasty with arachnoid preservation. Technique and long-term functional results in 44 consecutive adult cases - comparison with literature data. Acta Neurochir 144:1005-1019. https://doi.org/10.1007/s00701002-1004-8

89. Tisell M, Wallskog J, Linde M (2009) Long-term outcome after surgery for Chiari I malformation. Acta Neurol Scand 120:295299. https://doi.org/10.1111/j.1600-0404.2009.01183.x

90. Tubbs RS, Beckman J, Naftel RP, Chern JJ, Wellons JC 3rd, Rozzelle CJ, Blount JP, Oakes WJ (2011) Institutional experience with 500 cases of surgically treated pediatric Chiari malformation type I. J Neurosurg Pediatr 7:248-256. https://doi.org/10.3171/ 2010.12.peds10379

91. Vedantam A, Hansen D, Briceño V, Brayton A, Jea A (2017) Patient-reported outcomes of occipitocervical and atlantoaxial fusions in children. J Neurosurg Pediatr 19:85-90. https://doi.org/10. 3171/2016.8.peds16286

92. Wang Z, Wang X, Jian F, Zhang C, Wu H, Chen Z (2017) The changes of syrinx volume after posterior reduction and fixation of basilar invagination and atlantoaxial dislocation with syringomyelia. Eur Spine J 26:1019-1027. https://doi.org/10.1007/s00586016-4740-9

93. White AA 3rd, Panjabi MM (1978) The clinical biomechanics of the occipitoatlantoaxial complex. Orthop Clin N Am 9:867-878

94. Yin Y-h, Yu X-g (2015) Atlantoaxial facet dislocation and Chiari malformation. J Neurosurg Spine 23:390-391. https://doi.org/10. 3171/2015.1.SPINE154

95. Yu Y, Wang X, Zhang X, Hu F, Gu Y, Xie T, Jiang X, Jiang C (2013) Endoscopic transnasal odontoidectomy to treat basilar invagination with congenital osseous malformations. Eur Spine J 22:1127-1136. https://doi.org/10.1007/s00586-012-2605-4

96. Yuan SL, Xu HM, Fu LC, Cao J, Yang JK, Xi YM (2018) Sagittal atlantoaxial joint inclination and reduction index values for diagnosis and treatment of irreducible atlantoaxial dislocation. Indian $\mathrm{J}$ Orthop 52:190-195. https://doi.org/10.4103/ortho.IJOrtho_251_16

97. Zhang ZQ, Chen YQ, Chen YA, Wu X, Wang YB, Li XG (2008) Chiari I malformation associated with syringomyelia: a retrospective study of 316 surgically treated patients. Spinal Cord 46:358363. https://doi.org/10.1038/sj.sc.3102141

Publisher's note Springer Nature remains neutral with regard to jurisdictional claims in published maps and institutional affiliations. 